\title{
A Study on the Mechanism and Path of Cultural Creative Industry Cooperation between Fujian and Taiwan
}

\author{
Mei Chiao Lai \\ Department of Logistics Management \\ Fuzhou University of International Studies and Trade \\ Fuzhou, China \\ Hong Jun $\mathrm{Ou}$ \\ Department of Fine Art and Design \\ Fuzhou University of International Studies and Trade \\ Fuzhou, China
}

\author{
Xiao Chun Chen \\ Department of Fine Art and Design \\ Fuzhou University of International Studies and Trade \\ Fuzhou, China \\ Shih Ming Ou \\ Department of Logistics Management \\ Fuzhou University of International Studies and Trade \\ Fuzhou, China
}

\begin{abstract}
Culture creative industry is an important starting point to support and lead the economic structure optimization and upgrading. The purpose of the study is to use focus group interviews to figure out the mechanism and path of cultural creative industry cooperation. The study found that the key successful factors of cooperation are the government support, the participation of enterprises and cultural creative workers' mentality change. The mechanism and path of cooperation emerged from focus group interviews; they are Government autonomy guide, committed to the international brand, establishment of the service platform, set up service system, regulations issue and cultural creative talent team's formation.
\end{abstract}

Keywords-Culture creative industry; economic structure; Five-year Plan

\section{INTRODUCTION}

Culture creative industry is an important starting point to support and lead the economic structure optimization and upgrading, as well as the industry's top priority to become a pillar industry and enhance the national competitiveness of the country's soft power base.

Shao Longmei (2010) claims that the culture integration of Fujian and Taiwan is the linkage of five characteristics, in terms of Geographical, kinship, cultural margin, business edge, and legal convergence. The five cultural characteristics of Fujian and Taiwan separately are independent; collectively, it is also a culture combination of Fujian and Taiwan, or even constitutes a comprehensive cultural integration of the Taiwan Strait. Xiamen five bridges and its reflection constitute the "five circle", Homophonic "five yuan". Images from Shutterstock.com. said that the Xiamen five yuan hence got the name. It means that people of cross straits hope happy, people all over the world hope reunion, and hope Fujian and Taiwan reunion (five yuan). Due to the same culture, generations of southern Fujian people moved to Taiwan and result in the $75 \%$ Taiwan residents are southern Fujian people. The Southern Fujian people brought their culture to Taiwan, take root, grow, and strong, so as to deeply influence the formation and development of Taiwan culture. Therefore, if we can pay more attention to Fujian and Taiwan cultural and creative issues, and extensive exchange of viewpoints, in order to highlight the aesthetic concept of Chinese culture, shaping the unique Chinese life style, and it will be beneficial to the integration of economic, social and politics. Therefore, this study firstly used the focus group interviews to assess the willingness to communicate and cooperate each other and then to analyze the factors affecting their willingness to cooperate. Finally, it based on the analysis results to figure out the mechanism and path of cultural creative industry cooperation between Fujian and Taiwan.

\section{LITERATURE REVIEW}

\section{A. Cultural Creative Industry}

The United Nations Educational, Scientific and Cultural Organization (UNESCO) define that cultural industries are suitable for contents with intangibility and culture as essence. The industries in combination with creation, production and commoditization can be regarded as creative industries, sunrise or future oriented industries or content industries. UNESCO thinks the concept of cultural industries generally includes: printing, publishing, multimedia, audition and vision, photography and film production, which are equal to crafts and design. For some countries, this concept also includes architecture, visual and performing arts, sports, manufacture of music instruments, advertising and cultural tour. UNESCO mainly divides cultural and creative industry into cultural product, cultural services and intellectual property: Cultural products refer to books, magazines, multimedia products, software, record, film, videotape, audio and video entertainment, technology and fashion design; 
cultural services include performing services (theatre, opera house and circus), publishing, and publication, news and newspaper, transmission and construction services, audiovisual services (film sales and distribution, TV/radio programs and home video, film exhibition, cable, satellite and broadcasting facilities or ownership and operation of movie theatre), library service, archives, museums and other services.

In the aspect of Taiwan, the term of cultural and creative industry was first defined by the Executive Yuan in May, 2002. The definition of cultural and creative industry is: "It is the industry that originates from creative or cultural accumulation, penetrates the route and application of intellectual property and has the potential to create wealth and employment opportunity and promotes overall life cultural environment "(Council for Cultural Affairs 2002). In February 3, 2010, it made and published "Cultural and Creative Industry Development Law". This law defines cultural and creative industry refers to legal person, partnership, sole proprietorship or individuals that work on cultural and creative industry.

In 2010, China's Premier Wen Jiabao of the State Council listed cultural construction and cultural innovation as developing focuses. Similarly, administrative council of Taiwan also launches many related policies. Firstly, it published cultural and creative industry was one of the six important emerging industries in 2009. The culture creative industry is the key to support and lead economic structure optimization and upgrading. It also is the foundation of the "soft power" for national competition. Scholars Chen Wanfang, zheng qiao (2013), yan-ping huang, Zhu Xingting, ShuaiZhiJiang (2015) argued that industrial convergence breakthrough lies in the cultural creative industry, due to cultural and new economy are inseparable, without cultural and creative industries, there is no new economy.

\section{B. Intention of Cooperation}

The so called act intention refers to the subjective probability judgment of individual for taking a certain act. It reflects the intention of individual to take a certain act. The theory considers that, the most direct factor deciding an individual taking a certain act is behavioral intention. It also considers that all factors that may affect the act are representation of behavioral intention affecting act indirectly. Lots of researches pointed out that, under given conditions; the behavioral intention is the best way predicting individual behavior, and the behavioral intention and behavior have high correlation (Ajzen, 1991).

\section{Factors Affecting Intention}

Looking back the domestic essays about Unified Theory of Acceptance and Use of Technology (UTAUT), Zhang Hongchang (2004) research on Staff Acceptance of Enterprise Internal Network - Taking Sinosteel for Instance, the research takes UTAUT as the basis to modify the scale from the view of big scale traditional industry, and performs sampling layer by layer to carry out questionnaire to individual companies; the second is Cai Bingru (2004) who adopts UTAUT to discusses the factors affecting life insurance businessman taking mobile business system in the study of factors affecting life insurance businessman taking mobile life insurance system. However, in terms of cooperation intention of cultural creative workers, it lacks of relative research.

Performance expectancy, effort expectancy, and social influence are the factors affecting behavior intention in UTAUT model; and the facilitating conditions and behavior intention are the factors affecting use behavior. The above affecting relation would be affected by four disturbance variables of gender, age, experience, and voluntariness of use. The aspects and disturbance variable meanings in UTAUT model are described as follows.

\section{RESEARCH METHOD}

\section{A. Research Method}

This research firstly used focus group interviews to get first hand data from cultural creative workers to understand the advantages and difficulties to cooperate, and intention to cooperate each other between Fujian and Taiwan. Two main reasons for employing focus group interviews are that, focus group interviews can provide "a rich and detailed set of data about perceptions, thoughts, feelings, and impressions" of people in their own words (Stewart \& Shamdasani, 1990, p. 140). The second reason is that the focus group can find out not only what people think but also how and why they think the benefits and difficulties of cooperation take (Kitzinger, 1994). The more participants there are, the deeper the levels of disclosure that can be obtained.

\section{B. Research Object and Procedure}

The participants of focus group interviews were the workers of cultural and creative industry, specialist and scholars. A moderator introduces the topic and assists the participants to discuss it, encouraging interaction and guiding conversation. The participants usually share social and cultural experiences or share particular areas of concern. Three major procedures, pre-interview organization, interview-data collection and post-interview-data analysis, were included in the following flow chart (Figure 1). In this study, there were three focus group interviews conducted in order to reflect cultural creative workers' perspectives fully.

The guideline included five broad questions: (a) what factors causing the cooperation between Fujian and Taiwan? (b)What has been the advantage to you as a result of cooperation each other? (c) What has been the disadvantage to you as a result of cooperation each other? (d) What obstacles do you think inhibited the cooperate cross strait? (e) How do effectively cooperate and then enhance the performance of cultural creative industry ? Additional questions were asked as necessary to expand on issues or probe into areas being discussed (Krueger, 1998).

\section{Data Analysis}

The cooperation intention of cultural creative workers reflected in the focus group interviews was analyzed to assist understanding of the possibility of cooperation between 
Fujian and Taiwan. From the answer analysis it was hoped to gain insight into what was the situation of cooperation situation now, as well as the benefits, negative effects to participants to cooperation each other.

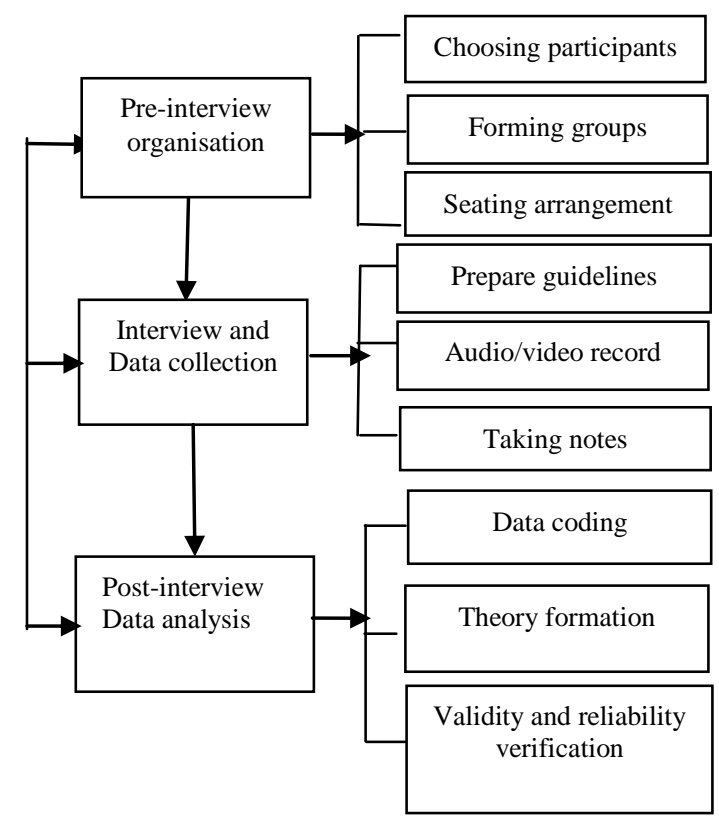

Fig. 1. Flow-chart of focus group interview.

\section{RESEARCH RESULTS}

According to the results of focus group interviews, the study figure out the mechanism and path of cultural and creative cooperation are divided into three aspects and addressed as follows:

\section{A. Government support}

1) Government autonomy guide: Fujian province government with the powerful resources, would issue some policies beneficial for Taiwan people, for example, provide the media propaganda guidance, multiple funding, the industrial development and counselling, market circulation and the development, talent cultivation and matching and industrial aggregation effect and so on policy support.

2) Regulations issue: The legislation of protecting cultural creative intellectual property rights and environmental protection, in order to eliminate creative imitation, and avoid causing environmental pollution and destruction.

3) Committed to the international brand: Fujian Government issued the "governance structures", which contain the introduction of Taiwan's production value into Fujian province, the learning of international communication and marketing methods, the understanding of international market demand for Oriental culture, the promotion of "across the value chain integration" and the linkage of the benefit of cultural creative industry between Fujian and Taiwan.

\section{B. Enterprises' Participation}

1) Establishment of the service platform: Aiming at promoting the innovation and entrepreneurship activities for the young people in Fujian and Taiwan, and use the local cultural resources to develop micro-cultural industry as well as to encourage people the entire world to bring resources into the community.

2) Set up service system: They are the investment of resources in art activities for people of Fujian and Taiwan community, balancing the development of urban and rural, in order to carry out the cultural rights, and to continue cultivating citizens' cultural quality.

\section{Cultural Creative Workers' Mentality Change}

1) Open mind: The cultural creative workers' should open their mind to share idea, viewpoint with their colleagues, brainstorming and communicate each other.

2) Cultural creative talent teams formation: Cultivating excellent creative talents for high school and College through training, communication, competition to accumulate culture material and experience and to promote the formation of talent teams of Fujian and Taiwan.

\section{CONCLUSION}

The cooperation of cultural creative industry between Fujian and Taiwan is effected by world economic situation, the external environment of social science and technology, government policy deployment and enterprise participation. The key successful factors of cooperation are the government support and the participation in enterprises and workers' mentality change.

\section{ACKNOWLEGEMENT}

It should express the deepest gratitude to Fujian Education Science "13th Five-year Plan" with serial number FJJKCGZ16-451 and name of "The study on the mechanism and path of cultural creative industry cooperation between Fujian and Taiwan".

\section{REFERENCES}

[1] Chen Wan-fang (2013). "Cultural creative industry between Fujian and Taiwan under the global economic crisis path and space research" (J), commercial economy, no. 4 (420).

[2] Guoli Xu (2016).An Exploration on Promoting Collaboration of Cultural Creative Industry between Fujian and Taiwan. International Conference on Contemporary Education, Social Sciences and Humanities (ICCESSH 2016), page285-286.

[3] Huang yan-ping, Zhu xing-ting (2015), "the new situation, deepen economic cooperation between Fujian and Taiwan issue to explore" (J), journal of south China normal university, 2015, (2).

[4] Ke Yong-hui, Zhao ming, Chen baibi (2011)."Fujian and Taiwan tourism and cultural creative industry integration development strategy research" (J), Journal of Shao guan college, 32 (9).

[5] Lin Li-Ya, Lin Guo-Chao (2016). Project Management for Cultural and Creative Goods. Proceeding of the 2nd International Conference of Arts, Design and Contemporary Education

[6] Meichiao Lai, Dan Liu, Lee Yang (2016). The Evaluation of the Acceptance and Intention of Using the Healthy Travel Mobile Guide 
System. Advanced in social science, Education Humanities Research, Volume 74.PP. 321-325.

[7] Mei-chiao Lai, Chin Jung Lin, Chien Jen Hung (2016). Assessment on the willing's to use food cold chain logistics under the applied transformation. Advanced in Economics, Business and Management Research, Volume 20. 2016, P.105-109.

[8] Shuai zhi-jiang (2015). "About improving the level of cultural creative industry between Fujian and Taiwan policy innovation system thinking" (J), southeast spread 7 (131).

[9] Venkatesh, V. (2000). Determinants of Perceived Ease of Use: Integrating Perceived Behavioral Control, Computer Anxiety and Enjoyment into the Technology Acceptance Model. Information Systems Research. 11 (4), pp. 342-365.

[10] Venkatesh, V., M.G., Morris, G. B. Davis and F. D. Davis (2003). User Acceptance of Information Technology: Toward A Unified View. MIS Quarterly, 27, 4 pp.425-478.

[11] Zheng qiao (2013). "Fujian and Taiwan culture industry talent resources development strategy research" (J), journal of Fujian institute of administrative total 142 . 